\title{
Thinking With Diagrams Whilst Writing With Words
}

\author{
Vimolan Mudaly \\ University of KwaZulu-Natal \\ mudalyv@ukzn.ac.za
}

\begin{abstract}
This paper describes how the visual aspects of mathematics influence the understanding of mathematical concepts. It attempts to contribute to the discussion that surrounds the ideas of visualisation, more specifically in mathematics classrooms. Two teaching interventions are described that may indicate how visual strategies can contribute to teaching in the classroom. An important finding of the research reported here is the ease with which dynamic geometry software can be used as a visual tool to develop analogical reasoning skills.
\end{abstract}

Mathematics teaching is generally conducted in a verbal way, where the teacher orally engages his or her learners with new or old concepts. These words are often abstract cues which the learners have to decipher, and with the added language problems that learners inherently have, these cues often confuse learners. Mathematics, being the king amongst abstract languages, conjures up nightmares in the minds of those that are mathematically challenged. The previous debates surrounding the abstract versus visual intrigued us, but the evidence provided in real life indicates that learning is aided by visual or pictorial images (Ball \& Ball, 2007; Hadamard, 1973; Kadunz \& Sträßer, 2004; Naidoo, 2007; Shear, 1985; Singh, 2007; Steen, 1990; Waisel, Wallace, \& Willemain, 1997).

It is common knowledge that a large part of our communication in daily life is dependent on visual imagery. Lowe (2000) states that the use of pictures to represent technical subject matter is not a new idea: "ancient pictures from many different countries show that visual information has long been an important means of communicating ideas about our world and how it works" (para. 2). Moreover these "mental images arise from perceptual representations that are created from stored information - not from information currently being registered by the senses" (Borst \& Kosslyn, 2008, p. 849). In other words, the existing a priori knowledge determines how these mental images are interpreted and communicated in daily life. From birth, children identify with objects based on the meanings they attach to what they see. They know who mum and dad is, and any other male or female would not be accepted with similar enthusiasm. Bells make beautiful sounds and should be vigorously shaken in order to produce music, hence the rattles that babies play with. Teenagers know that a "tick" on an item of clothing is highly sought after and makes a huge fashion statement. Adults identify road signs and make appropriate adjustments in their driving as they commute from point A to point B. A sudden appearance of a "road works ahead" sign (depicted by a man with a shovel), necessitates a particular driving strategy. Often, a visual survey of the environment immediately following such a sign will indicate some form of labour taking place on the road. A similar sign, placed incorrectly on a road will evoke a similar change in behaviour from a driver of a motor vehicle.

These visual images create in the mind of the viewer a particular reaction, not necessarily similar to the reaction created by the verbal utterance of a word. Viewed pictures often create clearer images in our minds because of the symbols attached to what we see, accompanied by other sensory perceptions. It is this act of creating images in the mind that gives credence to the words "seeing with the mind's eye" or "hearing with the mind's ear" (Kosslyn, Ganis \& Thompson, 2006, p. 195). More importantly, though is the idea that whilst "seeing with the mind's eye", the mind is capable of creating new information or the transformation of old knowledge (Mudaly \& Rampersad, 2010). Anecdotal evidence also shows that our mind reacts to mental or physical images in particular ways. For example, in the well-known Kanizsa 
illusion (see Figure 1), we see a whiter-than-white triangle, when no such triangle really exists. In this example, the mental cue directs our mind to some old information that we already know and an association is formed. In other words, we are seeing what we know. But I hasten to add that carefully drawn mind-maps, tables and diagrams aid in connecting facts that might not necessarily be understood through verbal means. Whilst physical and mental images are necessary, words and sentences are essential in recording of the information acquired through visual means.

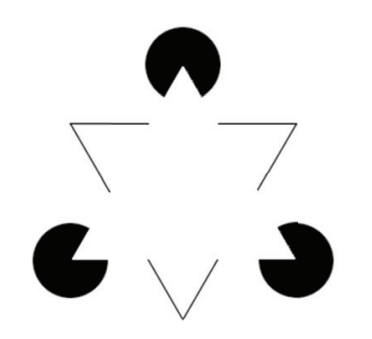

Figure 1: Kanizsa illusion

Just 'seeing' an object and its benefits is certainly not what this paper is all about. This paper is about the thinking and analysis that follows the viewing of an image, either physically or mentally. This paper is about visual literacy, which is much more than simply making a visual connection with some past experience. Aristotle (as cited in Zaskis, Dubinsky, \& Dautermann, 1996, p. 3) said that "no soul thinks without a mental image". The emphasis should actually be placed on the word thinks. Clearly, this is quite different from the word act. Davis and Maher (1997, p. 89) state that "the job of a mathematics student is to build up, in his or her mind, a collection of mathematical ideas". They further state that new ideas arise out of old ones (Davis \& Maher, 1997, p. 89). Whilst this does not appear to be a revolutionary idea, it reassures us that the provision of correct mental or physical visual stimuli is essential for the connection of old ideas to new, foreign ones. These visual stimuli act as tools to negotiate new ideas. English (1997) also reinforces this idea when she states that "one of the major goals of mathematics education is that children see the connections and relationships between mathematical ideas and apply this understanding to the solution of new problems" (p. 191). She argues that if we accept that learning is an active construction process based on recognising similarities between new and existing ideas, then it follows that children must develop meaningful and cohesive mental representations from the outset. English further argues that if children are to make the appropriate links to the new ideas, such representations must comprise the structural relations between ideas, not the superficial surface details.

The following example provides an idea of the use of analogical reasoning. This has not been tested with children, but it is expected that there is a reasonable resemblance to what can be expected in a classroom. Consider the question:

Water is pumped into a pool at a constant rate. The depth of the water (d) increases but not uniformly. In fact as $d$ increases for a certain period of time, the rate decreases and then dincreases at a uniform rate until the pool is filled. Sketch the cross section of the pool.

This is the target problem. In order to encourage learners to provide a reasonable solution, the following analogical problem can be given to them.

A rectangular swimming pool is being filled using a hosepipe which delivers water at a constant rate. A cross section of the pool is shown in Figure 2. Describe fully, in words, how the depth (d) of water in the pool varies with time, from the moment that the empty pool begins to fill.

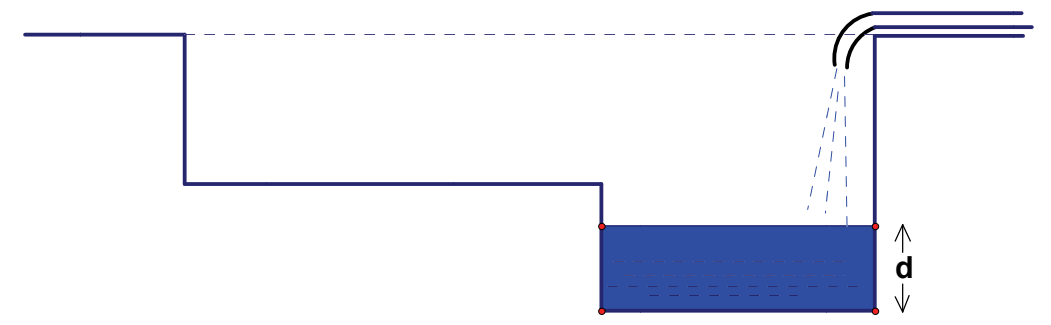

Figure 2: The pool 
With some guidance, it is expected that the learners would be able to provide the following solution: $d$ increases uniformly or steadily for the deep-end, and thereafter $d$ increases uniformly, but at a reduced rate until it is full.

It can now be anticipated that children may provide one of the two diagrams in Figure 3 as a solution to the target problem:

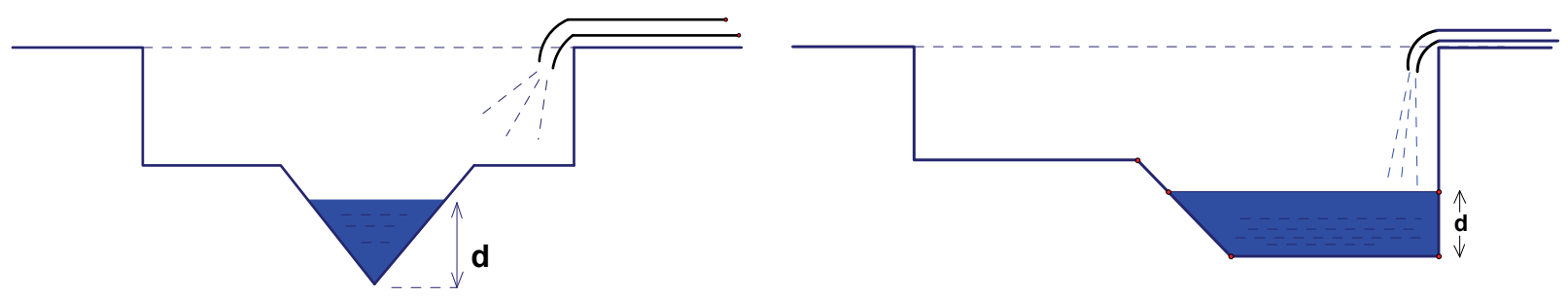

Figure 3: Possible solutions to the pool problem

In arguing for a connection between different ideas in order to establish meaningful learning, it must be considered within the context of Dreyfus's (1991) plea to give increased importance to visual reasoning. Wheatley (1997, p. 281) further argues that "visual reasoning plays a far more important role in the work of today's mathematicians than is generally acknowledged". This is similar to Lakoff's $(1987$, p. 278) argument that "understanding abstract structure is understanding structure in terms of schemas". Stokes (2002, p. 10) claims that

research reported in educational literature suggests that using visuals in teaching results in a greater degree of learning. The basic premise of this body of research is the concept of visual literacy, defined as the ability to interpret images as well as to generate images for communicating ideas and concepts.

Developing diagrams and mental images allows the individual to free up more mental space for new imaging and to construct new relationships (Wheatley, 1997, p. 285)

This paper also demonstrates the idea that children develop analogical reasoning skills (Gholson, Smither, Buhrman, \& Duncan, 1997, p. 151) if presented with a 'training problem' prior to their actual attempt at solving the real problem. Gholson et al. (1997, p. 151) state that

the representation that results from this type of acquisition process called the base. Following acquisition, they receive a transfer problem, called the target. If the target is similar to the problem presented in acquisition, children usually perform reasonably well in transfer relative to appropriate controls.

This paper further alludes to the fact that children are quite capable of solving difficult mathematical problems if their analogical reasoning skills are developed in a dynamic geometry environment.

It is perhaps at this point necessary to draw a distinction between that which is visualised and visual literacy. Visualised would refer to that which can be seen physically or mentally, like the mental picture that comes to mind at the mention of the word parabola. Visual literacy would refer to many pictures of parabolas, each one conjuring images that show parabolas having minima and maxima, the different shapes of the parabola, the effect of changing the values of $c$ and the coefficients of $x^{2}$ and $x$. An entire series of possibilities flashes through the mind. Of course, this depends on the extent to which one has completed the section on parabolas. The distinction may be subtle and may invoke some debate but Zaskis, Dubinsky and Dautermann (1996) critically reflect on this dichotomy. However, I take the stance that visual literacy is visualisation combined with logical thought. Zaskis et al. (1996) in a sense allude to this distinction when they describe their visualisation/analysis model (see Figure 4). They describe a process which begins with the visualisation of a picture or diagram, just some external stimulus that results in the mind seeing a picture. The next step they describe is that of analysis which involves a series of mental processes (similar to Piaget's reflective abstraction). The moment the learner moves from step 1 to step 2 they begin the process of visual literacy. The spiral nature of the model implies that the solution to a problem should begin with visualisation and then followed by an analysis process. 
The visualisation/analysis model as described by Zaskis et al. (1996) intimates that after A1, the learner makes new meaning of V1. Hence in re-assessing the picture or diagram, new information is added and therefore the learner makes greater sense of what $\mathrm{s} /$ he sees. This picture/diagram then can be called V2, and so the process continues. The conic shape implies that one cannot continue forever to derive new meaning out of similar pictures and diagrams.

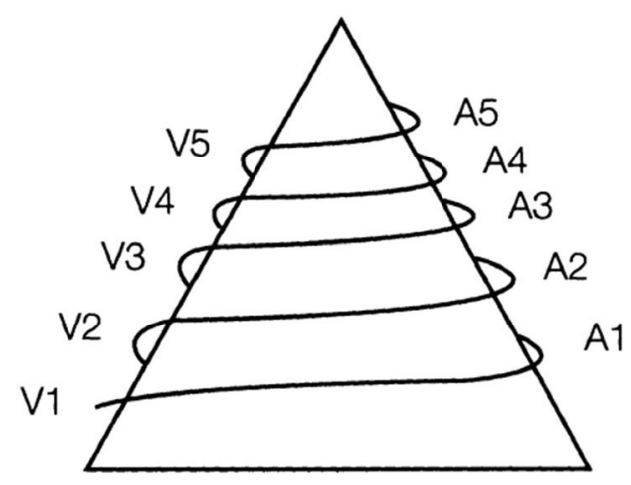

Figure 4: Visualisation/Analysis model. Source: Zaskis et al., 1996, p. 447

Consider as an example the function $\mathrm{f}(x)=\sin x$ in the domain $[0 ; 360]$. An immediate consequence of seeing this formula of the function would be to simply visualise the shape of the graph. This would represent the V1 in Figure 4. With a little thought, one may be able to mentally picture a function that begins at the coordinate $(0 ; 0)$, passing through the coordinates $(90 ; 1),(180 ; 0),(270 ;-1)$ and $(360 ; 0)$. This would then represent A1 in Figure 4. Now attempt to mentally visualise the function with formula $\mathrm{g}(x)=2 \sin \left(x+45^{\circ}\right)+1$. This requires mental manipulations that are not straight forward and cannot be construed to be a simple visualisation of the function. The ability to see the transformation from $\mathrm{f}(x)$ to $\mathrm{g}(x)$ is an exercise in visual literacy. It is possible that the visualisation schema might follow the following pattern:

$$
\mathrm{f}(x)=\sin x \rightarrow \mathrm{p}(x)=2 \sin x \rightarrow \mathrm{h}(x)=2 \sin (x+45) \rightarrow \mathrm{g}(x)=2 \sin (x+45)+1
$$

This is perhaps what Presmeg (1992) means when she talks about logical rationality which is intertwined with visualisation. This notion conveys the idea that if visual literacy is successfully taught then there is a natural tendency for the mind to engage in logical and rational thought at the sight of a picture or diagram. Visual literacy would refer to the internal processes that the mind engages in after viewing an external picture or diagram or a mental image. It is concerned with a product of some visual stimulus.

The process of rational and logical thought is influenced by the way the learner engages in the iterative processes (refer to Figure 5) of meaning construction (Mudaly \& Rampersad, 2010). On seeing a physical image (sight) or when thinking about an image (insight), a process of reflection using the learner's a priori knowledge takes place. Mental images influence the learner's physical, drawn image and vice versa. It seems that the new knowledge influences the next conjecture and the old incorrect ones become subsumed by a process of visual-analytical thinking. These images play an important role in the process of meaning construction.

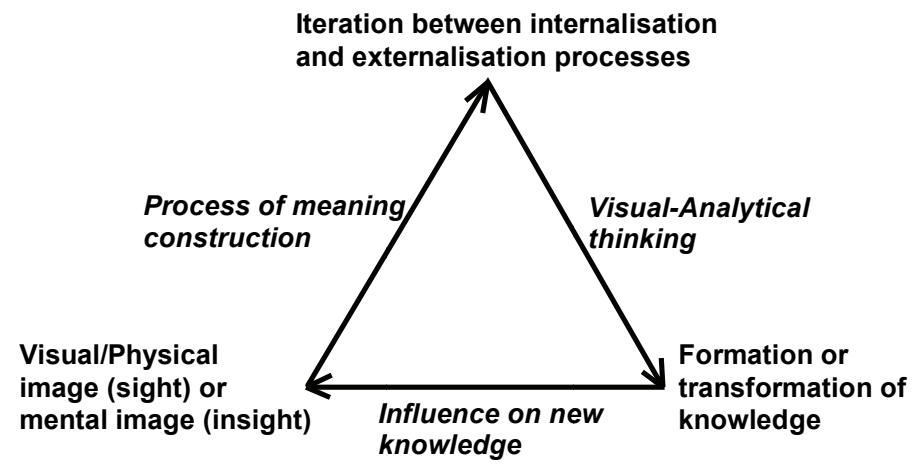

Figure 5: Processes involved in visualisation. Source: Mudaly \& Rampersad, 2010, p. 39 


\section{Two experimental tasks}

\section{Task 1}

The following problem (De Villiers, 2003, p. 23; Mudaly, 1999, p. 62; Mudaly, 2007, p. 68) was posed to Grade 9 learners in an intervention in a school in KwaZulu-Natal.

Sarah, a shipwreck survivor manages to swim to a desert island. As it happens, the island closely approximates the shape of an equilateral triangle. She soon discovers that the surfing is outstanding on all three of the island's coasts and crafts a surfboard from a fallen tree and surfs every day. Where should Sarah build her house so that the total sum of the distances from the house to all three beaches is a minimum. (She visits them with equal frequency.)

The previous discussions of this intervention in Mudaly (1999) and Mudaly (2007) examined learners' responses from a mathematical modelling perspective. This paper extends the analysis to a visualisation perspective. The question "Where do you think that Sarah should build her house?" elicited a common response among most learners, namely that Sarah should build her house at the centre of the triangle. The learners were asked why they felt that the house should be built at the centre. Kumarasen, for example, responded by saying that: "...if you build anything in the centre then there is always a short distance around it". Manivasan, whose reason was " ...because everything will be equal". Rowan believed that it should be at the centre because "it will be close ... it will be the same distance to all the beaches" and therefore the sum will be a minimum. Karishma felt that the sum would be a minimum if the house was at the centre of the triangle because "it will be closer to all three beaches". Without a diagram or a picture to guide them the learners attempted to picture in their minds a possible island and a probable solution. A possible explanation here relates to the fact that these learners used their a priori knowledge of circles to envision a point that was equidistant to the three sides of the triangle. Equality of length was instantly equated to the idea that a radius was equal in a circle.

The next task required the learners to investigate the problem with a ready-made sketch on Sketchpad (see Figure 6) where the distances to the sides and their sum, was already provided. Learners were asked to move ("drag") point $\mathrm{H}$ (the position of the 'house') around in the triangle and to observe whether any changes were taking place. Providing an already constructed diagram, instead of the learners first constructing it, was prudent because it saved much time.

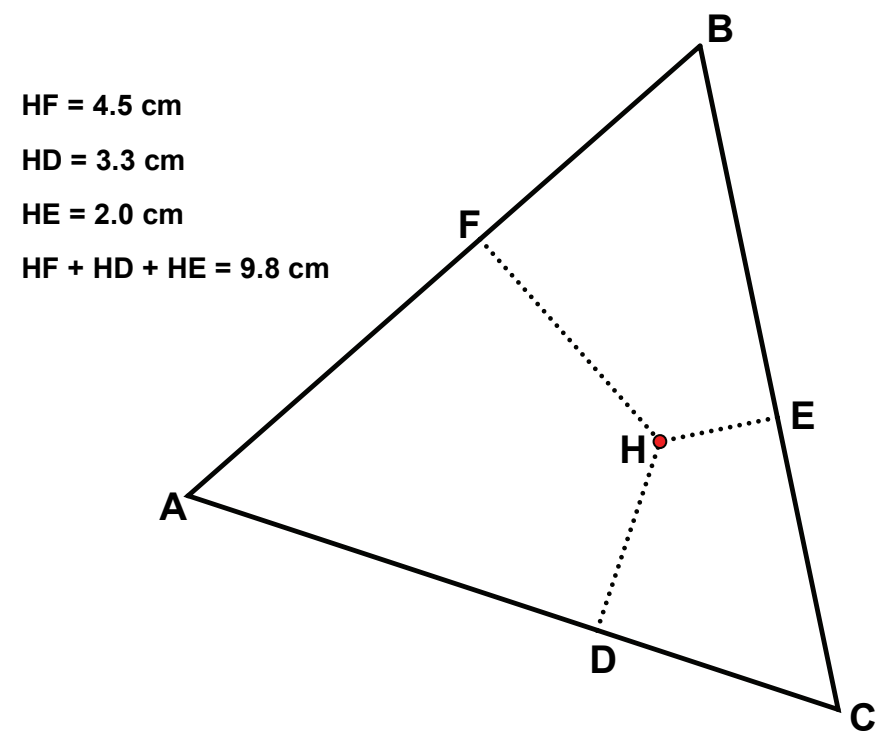

Figure 6: Learners' attempt to find the optimum position of the house

On seeing the picture the learners were further convinced that the house should actually be built at the centre of the triangle. They were then prompted to drag the point $\mathrm{H}$ around and observe the measures on the left. After the learners had moved the point around, they had to make a conjecture regarding their 
observations. All the learners found that when moving the point around, the distances to the three sides of the triangle changed, but their sum did not. All of them seemed quite surprised at the result. Kumarasen stated that "at first you think it should be at the centre and the sum will be small. But now it can be anywhere". This could probably be attributed to the result so clearly contradicting their initial expectation. It was also noticed that the majority of them began to smile after they came up with their conjecture, which indicated that the discovery was not an unpleasant, but a pleasant surprise.

The dynamic nature of Sketchpad allowed the learners to 'see' and analyse several different diagrams and its resultant sum in a matter of a few minutes. Although, similar results could have been obtained using pencil and paper constructions, Sketchpad simply facilitated this process far quicker than would have been expected. But the idea that it conveys is that without seeing the diagrams and analysing the results, as it appeared on the screen may not have achieved a high level of conviction in the minds of the learners. More importantly though, it was the visual cues that the learners saw on the computer screen that convinced them of the result. There was iteration between the physical and mental images and, although this process occurred very quickly, it enabled the learners to analytically create new information.

\title{
Task 2
}

In a second investigation Grade 10 learners were asked the following question (De Villiers, 2003, p. 27; Mudaly, 1999, p. 114; Mudaly, 2007, p. 70):

\begin{abstract}
In a developing country like South Africa, there are many remote villages where people do not have access to safe, clean water and are dependent on nearby streams or rivers for their water supply. With the recent outbreak of cholera in these areas, untreated water from these streams and rivers has become dangerous for human consumption. Suppose you were asked to determine the site for a water reservoir and purification plant so that it would be the same distance away from four remote villages. Where would you recommend the building of this plant?
\end{abstract}

As was the case in the previous task, these student responses are theorised using a visualisation framework of analysis as compared to the discussion in Mudaly (1999) and Mudaly (2007). The intention of the task was to teach learners about cyclic quadrilaterals (which they would normally encounter in their Grade 11 year). Therefore all diagrams had to be provided, otherwise the learners would have had to already have known the properties of the cyclic quadrilateral and this would have contradicted the purpose of the investigation.

The diagram they saw on the screen with the easy-to-use buttons is shown in Figure 7.

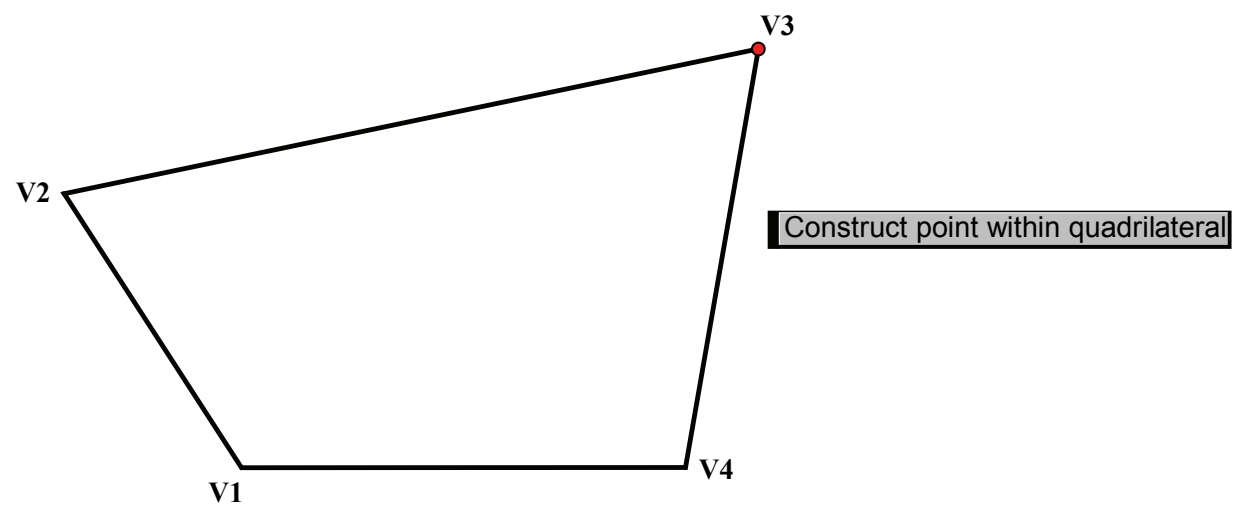

Figure 7: Learners trying to find the centre of the quadrilateral

The initial question attempted to determine whether the learners had any ideas about the solution. The researcher was aware that the learners had insufficient information to construct a reasonable solution. So when they were asked to predict a site for the reservoir, all learners "guessed" a solution somewhere in the "middle" of the quadrilateral (similar to Task 1), but none could find a precise solution. More importantly, few of them even thought of or tried to test their solution. The inaccuracy of their visual 
perception created surprise when the learners later discovered that their conjectures were not correct. It is not strange that in both instances the learners felt that the object should be constructed in the 'middle' or 'centre'. It is highly probable that learners think in terms of a circle and perhaps one should be asking why only the centre implies equidistant to all points. Is it perhaps, that learners are only exposed to symmetrical geometric shapes in classrooms? Nonetheless, their previous knowledge systems indicated to them that the point was in the middle. In attempting to analyse the contextual problem the learners visualised a quadrilateral where the point "somewhere in the middle" would be ideal for the building of the reservoir. It can be conjectured that previous images of working with circles contributed to their responses.

They were then asked to move V3 so that they could find the point at which the distances to the vertices were the same. This proved to be a tricky task. It was evident that the learners had no idea as to how they could proceed further with finding an accurate solution to the problem. It was fine that they knew that the point could be dragged around to find an approximate solution, but determining points in this way is time consuming as well, and if one looks at finding solutions correct to a few decimal places then finding accurate solutions is essential. Moreover, the act of dragging and viewing the images on the screen had the effect of showing them that their initial conjecture was incorrect. This must have resulted in a mental dilemma, where they were fairly convinced that the point should be "somewhere in the middle" and then discovering that this is not the case. New mental images had to be created but with no definitive position for the point in question.

Instead of considering four villages, the learners were asked to work with two. The simplified version of the problem was easy to solve for the learners. They could easily visualise the solution - which they knew to be the midpoint of the segment between the two villages. But by using the idea that the midpoint may not be suitable as a real-life solution, the learners were asked if they could determine another point which was also equidistant from the two villages. The purpose was to investigate whether learners could find other points and realise that there were infinitely many and the points all lay in a line, that is, the perpendicular bisector. It should be pointed out to the reader that traditionally in South Africa, the perpendicular bisector is usually introduced in Grade 8 or 9 (or sometimes earlier), but only as a construction. In other words simply as a line that passes perpendicularly through the midpoint of a line segment, but its equidistance properties are traditionally never investigated (and perhaps only alluded to in passing).

The learners were quite clear about the fact that if one point was not suitable then another could be used another point that satisfied the condition of being equidistant from two points. The researcher was initially unsure whether the learners would be able to make the deduction that all points that are equidistant from two points will lie on the perpendicular bisector. But the learners made this connection to the perpendicular bisector quite easily. Notice the analysis that had taken place. They considered the midpoint to be the solution and then discovered that there were in fact many solutions. The constant iteration between visualisation and analysis lead them to eventually conclude that the any point on a perpendicular bisector would be equidistant to the two end points of the segment (refer to Figure 8).

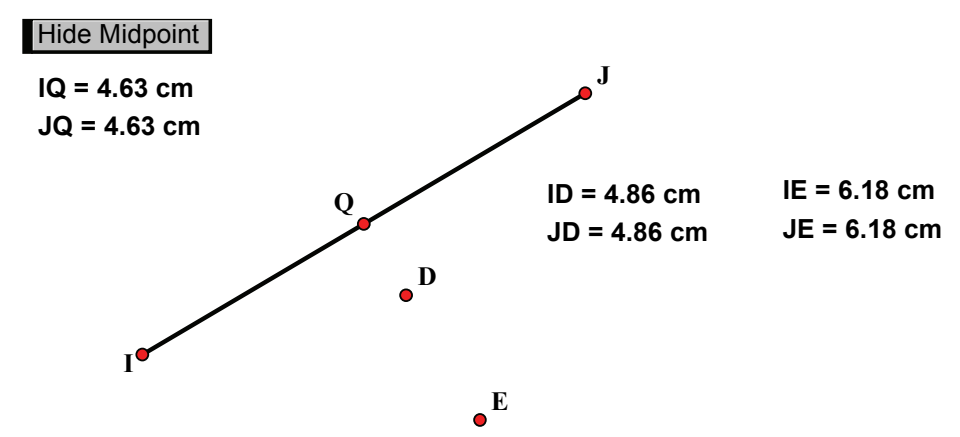

Figure 8: Using the perpendicular bisector

At this point the researcher was interested to see whether the learners would now immediately use the newly acquired concepts of equidistance and perpendicular bisector they arrived at for the problem with the four villages. All learners confidently stated that we should use the perpendicular bisectors of each 
side of the quadrilateral. As has been expected, the learners had used their knowledge of the perpendicular line between two points to conjecture a result for the four points. The learners showed no particular emotion when they discovered that the four perpendicular bisectors met at a common point. It was as if they had expected it to happen and it was taken for granted that these lines would meet. None of them stated that this result really surprised them; in fact, most of them conveyed the idea that this was expected. This is perhaps also indicative of the social context within which learners construct meaning for problems given to them. Learners intuitively sense that the problem would not have been asked if there was no precise solution already "pre-existing", and this kind of (unrealistic) anticipation is likely to become a determinant force in their behaviour, unless they are given sufficient experiences to counter it. Furthermore, it implied that their 'new discovery' was in line with what they already 'knew', so there was no reason to doubt or question their finding. The physical image on the screen simply corroborated their existing knowledge.

Next the researcher informally introduced the learners to the circumcircle, but no formal definitions of circumcentre and circumcircle were given. A circle was constructed from the point of concurrency (the circumcentre) as center with the circumference passing through one of the vertices of the cyclic quadrilateral. The learners showed surprise in their facial expressions and the way in which they responded when they saw that the circle now passed through all the vertices of the quadrilateral. The diagram below (Figure 9) is an example of what the learners saw on the computer screen as they worked with the circumcircle.

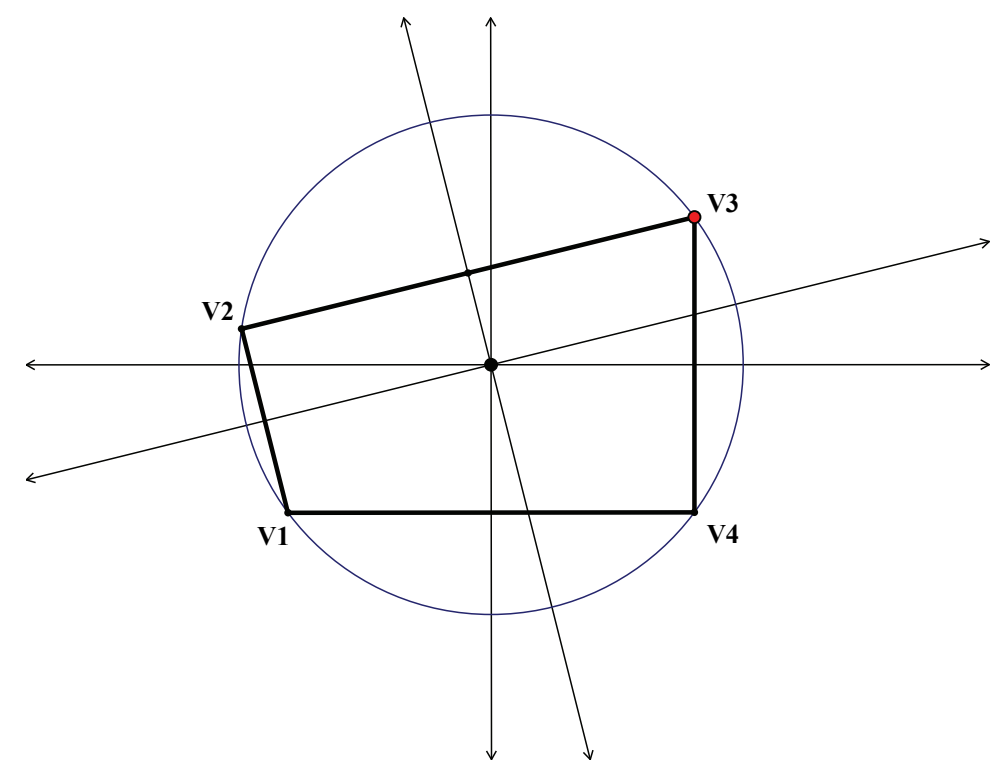

Figure 9: Circle now passes through all the vertices of the quadrilateral

The intention of the next aspect was mainly to see if learners would realise that the perpendicular bisectors of a quadrilateral were not necessarily always concurrent, that is, that for a quadrilateral it was not always possible to find an equidistant point. The dynamic facility of Sketchpad not only facilitated this finding quite easily, but assisted some learners to realise that an equidistant point would only exist when the circle passed through the four vertices (that is, the quadrilateral is cyclic).

With Sketchpad it was easy to change the size and shape of the given quadrilateral, so that the learners could observe whether the perpendicular bisectors were concurrent and whether the circumference of the circle still passed through the vertices of the quadrilateral. Whilst moving a vertex of the quadrilateral around the learners discovered that the result they expected was not always true. It can be conjectured that this created another mental dilemma for them. By moving the vertex to various positions, a new mental image was formed. They now discovered that the result was only true when the vertices of the quadrilateral lay on the circumference of a circle. It must be noted that this constant iteration between the different images was creating new knowledge that may have been difficult to achieve if pencil and paper methods were used. 
The learners were next presented the same problem, but now within the context of a triangle. The questions that they were asked were not different from the previous ones and the responses they made were, as expected, in accordance with what they saw in the previous case. The learners confidently responded that they would again use perpendicular bisectors to locate the required point. In fact, the level of their conviction was very high and this could be determined from the way they responded and the language they used. They were convinced that the perpendicular bisectors would be concurrent if the vertices were concyclic. This was just an extrapolation of the previous result. This was Schofield's response:

Schofield: It must be the same for the four-sided figures.

Researcher: What do you mean?

Schofield: For the quadrilateral it only worked for some...when the circle touched the four corners...it might be the same for the triangle.

Faeeza had made similar responses. But Faeeza's response was quite interesting. She initially stated that by constructing the perpendicular bisectors we could find the most suitable position. But she immediately changed her mind to include something that she had just learned for quadrilaterals - a qualification she felt was necessary. She felt that the perpendicular bisectors would only meet if a circle passed through the vertices of the triangle. One can imagine the pictures that were being processed in their minds. Their new conjectures were becoming influenced by the new knowledge they had acquired in the previous task. Interestingly enough, their mental images were changing as they viewed the Sketchpad diagrams on the screen. These images started with an image that represented their conjecture and changed as they viewed the results on the screen. It is this analysis that ensured that meaning-making was occurring.

Of course, when they constructed the perpendicular bisectors they could see that the perpendicular bisectors were concurrent and the vertices were concyclic for all triangles that they created by dragging a vertex. Although this may not represent every possible triangle but it was a sufficiently large number to convince them. They initially doubted their observations, perhaps because it contradicted something they just learned. Schofield was initially very sure. His conviction arose from his experience with the quadrilateral. He was surprised to see that the lines were always concurrent for a triangle, but was still eager to try it for more triangles: "No...I think move it a bit more". He was still unconvinced that the result was true for all triangles. After working through more examples, his response to the question "are you satisfied that the perpendicular bisectors are always concurrent?", he replied "Yes...but I never would have guessed that!". This process also took only a few minutes but he was very convinced because he saw the changes on the computer screen ("No doubt...I saw it myself!"). The implication of this may be that he would not have accepted the truth of the result had he been just told, but the fact that he could dynamically see the result convinced him that the result was true. A more pertinent implication is the way these learners experienced the acquisition of new knowledge.

\section{The need for proof}

The researcher found that the majority of learners expressed a desire for an explanation in the first task. In fact $94 \%$ of the learners said that they would want an explanation and only one learner took a while before saying that she would also like an explanation.

It seemed that despite being convinced, they also wanted to understand why the result is true. It seemed that wanted something more than just being able to observe and accept the validity of the statement. The researcher acknowledges that by asking the question "Do you want to know why this is true?" the learner may have been led to answering in the affirmative. However their body language and response seemed to indicate that they truly wanted to know why. Although all the learners were absolutely sure of the statement, they nevertheless seemed to express a need for further understanding. These are some of the learner responses to the question: "Why do you want an explanation for this?".
Rodney: To satisfy my curiosity.
Manivasan : So I can understand it. [his emphasis]
Karishma: Because I'm curious and I'd like to know what's going on.

Debashnee: Because I'm a curious person and I would like to find a solution for things. I would like to do the same for this. 
Again it would seem that there was a deeper urge to find an explanation rather than to check whether the result was really true.

It further seems clear that the learners' desire for further explanation or a deeper understanding had not been satisfied by the empirical exploration on computer. This exploration only seemed to convince them, but did not appear to have satisfied some deeper need for explanation and understanding. In fact, it is probable that the visual evidence only spurred them on to desire a more formal deductive proof.

\section{Conclusion}

This paper does not investigate the way learners mentally structure the mathematics that they learn. But, it did provide insight into the idea that given the opportunity to segment a difficult mathematical question into little, more solvable ones made the learning and content more meaningful to them. The visual strategies employed in attempting to elicit responses that directed their learning seemed to work well as they constructed hypotheses and tested them. New knowledge in the form of visual images (as they worked on Sketchpad) was constantly replacing the old untested hypotheses. Sketchpad provided the visual justification for them to make specific conjectures, and having high levels of conviction did not necessarily remove the need for proof. Understanding generally was attained after 'seeing' the solution and the visual impact of the dynamic diagrams allowed the learners to quickly draw adequate conclusions. Whilst I did not get students to attempt these problems using pen and paper, I would conjecture that they would have taken far more time to complete the tasks. Clearly, "effective mathematical learning requires active student participation in meaningful experiences" (English, 1997, p. 3).

More importantly, the research showed that 'seeing' the pictures, albeit through the use of Sketchpad, enhanced the learning tremendously by creating meaningful opportunities for the learners to grasp the concepts presented. The second task demonstrated that analogical reasoning skills can easily be developed using Sketchpad. The use of simpler problems to eventually answer more complex questions was attained through the power of the visuals and the effective use of the dynamic geometry software.

\section{References}

Arcavi, A. (2003). The role of visual representations in the learning of mathematics. Educational Studies in Mathematics, 52, 215-241. doi: 10.1023/A:1024312321077

Ball, B., \& Ball, D. (2007). Visualising geometry. Mathematics Teaching, 205, 4-5.

Borst, G., \& Kosslyn, S. M. (2008). Visual mental imagery and visual perception: Structural equivalence revealed by scanning processes. Memory \& Cognition, 36(4), 849-862. doi: 10.3758/MC.36.4.849

Davis, R. B., \& Maher, C. A. (1997). How students think: The role of representation. In L. D. English, (Ed.), Mathematical reasoning: Analogies, metaphors, and images (pp. 93-115). Mahwah, NJ: Lawrence Erlbaum.

De Villiers, M. (2003). Rethinking proof with the Geometer's Sketchpad (2nd ed.). Emeryville, CA: Key Curriculum Press.

Dreyfus, T. (1991). On the status of visual reasoning in mathematics and mathematics education. In F. Furinghetti (Ed.), Proceedings of the $15^{\text {th }}$ Annual Meeting of the International Group for the Psychology of Mathematics Education (Vol. 1, pp. 33-48). Assisi, Italy: PME.

English, L. D. (1997). Analogies, metaphors, and images: Vehicles for mathematical reasoning. In L. D. English (Ed.), Mathematical reasoning: analogies, metaphors, and images (pp. 3-18). Mahwah, NJ: Lawrence Erlbaum.

English, L. D. (1997). Children's reasoning processes in classifying and solving computational word problems. In L.D. English (Ed.), Mathematical reasoning: Analogies, metaphors, and images (pp. 191-246). New Jersey, NJ: Lawrence Erlbaum.

Gholson, B., Smither, D., Buhrman, A., \& Duncan, M. K. (1997). Children's development of analogical problem-solving skill. In L. D. English (Ed.), Mathematical reasoning: Analogies, metaphors, and images (pp. 149-190). Mahwah, NJ: Lawrence Erlbaum.

Hadamard, J. (1973). The mathematician's mind: The psychology of invention in the mathematical field. Princeton, NJ: Princeton University Press. 
Kadunz, G., \& Sträßer, R. (2004). Image - Metaphor - Diagram: Visualisation in learning mathematics. In M. J. Hoines \& A. B. Fuglestad (Ed.), Proceedings of the $28^{\text {th }}$ Conference of the International Group for the Psychology of Mathematics Education (Vol. 4, pp. 241-248). Bergen, Norway: PME.

Kosslyn, S. M., Ganis, G., \& Thompson, W. L. (2006). Mental imagery and the human brain. In Q. Jing, M. R. Rosenzweig, G. d'Ydewalle, H. Zhang, H. C. Chen, \& K. Zhang (Eds.). Progress in psychological science around the world. Vol. 1: Neural, cognitive and developmental issues (pp. 195-209). New York, NY: Psychology Press.

Lakoff, G. (1987). Women, fire and dangerous things: What categories reveal about the mind. Chicago: University of Chicago Press.

Lowe, R. (2000). Visual literacy and learning in science. Columbus, OH: ERIC Clearinghouse for Science Mathematics and Environmental Education. Retrieved from http://www.ericdigests.org/2003-1/visual.htm

Mudaly, V. (1999). Pupils' needs for conviction and explanation within the context of dynamic geometry. (Unpublished masters dissertation). University of Durban-Westville, Durban.

Mudaly, V. (2004). The role and use of Sketchpad as a modeling tool in secondary schools. (Unpublished doctoral dissertation). University of KwaZulu-Natal, Durban.

Mudaly, V. (2007). Proof and proving in secondary schools. Pythagoras, 66, 64-75.

Mudaly, V. \& Rampersad, R. (2010). The role of visualisation in learners' conceptual understanding of graphical functional relationships. African Journal for Research in Mathematics, Science and Technology Education, 14(1), 36-48.

Naidoo, J. (2007). The effect of social class on visualisation in geometry in two KwaZulu-Natal schools, South Africa. (Unpublished masters dissertation). University of Nottingham, Nottingham.

Presmeg, N. C. (1992) Prototypes, metaphors, metonymies and imaginative rationality in high school mathematics. Educational Studies in Mathematics, 23, 595-610. doi: 10.1007/BF00540062

Shear, J. (1985). Visual thinking, algebraic thinking, and a full unit-circle diagram. Mathematics Teacher, $78(7), 518-522$.

Singh, R. I. (2007). An investigation into learner understanding of the properties of selected quadrilaterals using manipulatives in a grade eight mathematics class. (Unpublished masters dissertation). University of KwaZulu-Natal, Durban.

Steen, L. A. (1990). On the shoulders of giants: New approaches to numeracy. Washington, DC: National Academy Press.

Stokes S. (2002). Visual literacy in teaching and learning: A literature perspective. Electronic Journal for the Integration of Technology in Education, 1(1), 10-19. Retrieved from http://ejite.isu.edu/Volume1No1/pdfs/stokes.pdf

Waisel, L. B., Wallace, W. A., \& Willemain, T. R. (1997). Using diagrammatic representations in mathematical modeling: The sketches of expert modelers. In Technical Report of the AAAI 1997 Fall Symposium on Reasoning with Diagrammatic Representations. Troy: Massachusetts Institute of Technology.

Wheatley, G. H. (1997). Reasoning with images in mathematical activity. In L. D. English (Ed.), Mathematical reasoning: Analogies, metaphors and images (pp. 281-298). Mahwah, NJ: Lawrence Erlbaum.

Wheatley, G., \& Reynolds, A. (1997). A student's imaging in solving a non-routine task. Teaching Children Mathematics, 4(2), 100-104.

Zaskis, R, Dubinsky, E., \& Dautermann, J. (1996). Coordinating visual and analytic strategies: A study of students' understanding of the Group $\mathrm{D}_{4}$. Journal for Research in Mathematics Education. 27(4), 435-457. 